\title{
THE PARADOXICAL AND TIME-VARYING EFFECTS OF FAMILY OWNERSHIP ON ABSORPTIVE CAPACITY
}

\author{
JOSIP KOTLAR \\ Department of Entrepreneurship, Strategy and Innovation, Centre for Family Business \\ Lancaster University Management School \\ Lancaster, LA1 4YX, UK
}

ALFREDO DE MASSIS

Lancaster University Management School, UK

FEDERICO FRATTINI

Politecnico di Milano, Italy

NADINE KAMMERLANDER

WHU - Otto Beisheim School of Management, Germany

\begin{abstract}
We present a theory of family ownership as a driver of the heterogeneity (between-firm differences) and variability (within-firm differences over time) of absorptive capacity (AC). We introduce the concepts of motivation and implementation gaps to explain why, paradoxically, family ownership can cause both upward and downward divergences in AC.
\end{abstract}

\section{INTRODUCTION}

In increasingly dynamic and competitive environments, the capacity to acquire and exploit external knowledge - that is, absorptive capacity (AC; Cohen \& Levinthal, 1990) - is crucial for firms to innovate, renew their competitive advantage, and sustain performance (Lewin et al., 2011; Schildt et al., 2012; Vasudeva and Anand 2011; Volberda et al., 2010; Wales et al., 2013). Scholars have observed the benefits of AC and the considerable heterogeneity in this capacity across firms operating under similar external conditions (Cassiman an\&d Veugelers, 2006; Jansen et al., 2005; Lane et al., 2001; Yayavaram \& Ahuja, 2008). Theoretically understanding the firm-level antecedents and mechanisms of AC has therefore become a key objective in management and organization research (see Lane et al., 2006; Todorova \& Durisin, 2007; Volberda et al., 2010).

This literature, however, so far does not consider the crucial influence of firm ownership, in particular family ownership. It is surprising that, with increasing research attention being focused to uncover the internal drivers of AC, scholars have examined the role of managers independently of firm ownership (Lane et al., 2006; Nag \& Gioia, 2012; Todorova \& Durisin, 2007; Volberda et al., 2010). Similarly, empirical research places considerably more emphasis on widely held, professionally managed firms (e.g., Ben-Oz \& Greve, 2012; Lane \& Lubatkin, 1998; Rothaermel \& Alexandre, 2009) than on family owned firms that are prominent in most economies (La Porta et al., 1999). By ignoring firm ownership, existing theories tend to overlook the role of powerful actors who may influence key strategic decisions (Carney, 2005; Chrisman \& Patel, 2012) and the emotional concerns possibly deriving from their affective and social ties with the firm (Cruz et al., 
2010; Gómez-Mejía et al., 2007). Introducing family ownership and integrating emotional aspects in the theory of AC enables moving beyond the structural and overly rational views of this capacity (Lane et al., 2006; Volberda et al., 2010). It enables a deeper understanding of the cognitive processes that lead some firms to succeed in changing technological environments while others are blindsided by the new knowledge and fail (Levinthal \& March, 1993; Zahra \& George, 2002).

To address outstanding issues in the literature and recent calls for deeper theoretical understanding of the internal antecedents of AC (Lane et al., 2006; Volberda et al., 2010), we aim to integrate and extend the literatures on $\mathrm{AC}$ and family firms by answering the following questions: What are the mechanisms through which family ownership influences the level of firm AC? Under which conditions is family ownership beneficial or detrimental to potential and realized AC? How does the influence of family ownership on AC evolve over time?

\section{THE MISSING LINK BETWEEN FIRM OWNERSHIP AND AC}

$\mathrm{AC}$ is the ability to acquire and exploit external knowledge to extend or renew existing knowledge stocks and use such resources to innovate and gain a competitive advantage (Cohen \& Levinthal, 1990; Lane et al., 2006; Zahra \& George, 2002). In the following, we build on Zahra and George's (2002) distinction between potential AC, which refers to the knowledge funnel that determines which external information crosses the firm's boundaries (i.e., knowledge acquisition, Lane \& Lubatkin, 1998; Van den Bosch et al., 1999), and realized AC, which refers to transforming the externally acquired knowledge into valuable outputs (i.e., knowledge exploitation, Narasimhan et al., 2006; Tsai, 2001).

Research on AC has largely been developed in the context of widely held, professionallymanaged firms, thereby disregarding the important influence of firm owners and assuming they have limited willingness and ability to influence the decisions and processes involved in the use of external knowledge. This assumption is problematic considering that firm owners can exert considerable influence (Connelly et al., 2010; David et al., 2001; Hoskisson et al., 2002). This lack of integration is especially an issue when considering that family ownership, predominant in most countries and industries (e.g., La Porta et al., 1999), can create strong affective and social ties within the firm, ultimately implying that socio-emotional considerations play a prominent role in decisionmaking (Gómez-Mejía et al., 2007). This calls into question the overly rational view of AC developed in prior research (Lane et al., 2006; Volberda et al., 2010), suggesting that only limited understanding of $\mathrm{AC}$ is achieved when not explicitly taking into account the role of family owners, including their emotions and power, in shaping firm behavior.

\section{FAMILY OWNERSHIP AS AN INTERNAL DRIVER OF AC}

Although no studies directly examine the influence of family ownership on AC, research in related areas indicates the importance and potential complexity of this relation. Prior studies examine a number of aspects related to family ownership that, albeit indirectly, have implications for AC. For example, there is considerable interest in the influence of family ownership on R\&D investments (e.g., Block, 2012; Chrisman \& Patel, 2012; Gómez-Mejía et al., 2013; Patel \& Chrisman, 2014; Sirmon et al., 2008), typically seen as a proxy of a firm's stock of prior knowledge and often associated with AC (Cohen \& Levinthal, 1990; Lane et al., 2001). R\&D investments are however 
only a weak predictor of AC (Lane \& Lubatkin, 1998; Tortoriello, 2015; Volberda et al., 2010) and such emphasis overshadows other important aspects of the processes through which firms acquire and exploit external knowledge. Research on technology acquisitions (Kotlar et al., 2013) indicates important consequences of family ownership on potential AC. Relatedly, research examining knowledge internalization within the family (Chirico \& Salvato, 2014) and knowledge recombination in the family firm (Patel \& Fiet, 2011) offers further insights into the knowledge structures of family firms, which are critical to their ability to acquire external knowledge (Volberda et al., 2010). Some authors provide insights on the influence of family ownership on realized AC such as Block (2012) who focuses on the ability to turn R\&D investments into patents, Patel and Chrisman (2014) who examine explorative and exploitative R\&D investments, and König et al. (2013) who offer a model of organizational constraints to discontinuous technology adoption.

Collectively, prior research suggests that family ownership is likely to be an important antecedent of a firm's AC. However, most prior studies do not differentiate the different effects of family ownership on knowledge acquisition and exploitation. Moreover, no theoretical framework acknowledges the simultaneous positive and negative effects that operate through different mechanisms. Finally, knowledge of how the influence of family owners varies across populations of firms is nascent at best (e.g., Chua et al., 2012). For these reasons, it is not possible to extrapolate from existing research to form an overarching framework that explains the mechanisms through which family owners influence AC and the conditions under which family ownership is beneficial or detrimental to the firm capability to acquire and exploit external knowledge. To address this issue, we develop a model of the influence of family owners on firm behavior and use this to build our analysis of its consequences on AC.

\section{INFLUENCE OF FAMILY OWNERS}

Conceptualizations of family ownership and organizational consequences vary across theoretical frameworks and empirical studies, ranging from broad concepts such as socio-emotional wealth (Gómez-Mejía et al., 2007) and familiness (Habbershon et al., 2003) to more granular conceptualizations deconstructing the influence of family owners into its multiple components (e.g., the "Four Cs" model, Miller \& Le Breton-Miller, 2005; the "Three Ps", Carney, 2005).

Our conceptualization converges toward two main constructs, emotional attachment and power concentration, that respectively qualify the role of family owners in governing the firm's strategy and structure. In particular, we propose that the influence of family owners on the strategy and structure of a firm will vary depending on the strength of their emotional attachment to the firm and the degree of power concentration in the family. As several scholars note, strategy and structure are inextricably linked and adjust to one another in the long term (Chandler, 1962; Hall \& Saias, 1980), so we do not rule out the existence of reciprocal effects between the two dimensions. However, these dimensions highlight different aspects of family influence that can vary independently from one another, at least in the short term. Thus, elaborating on these two dimensions separately facilitates theorizing about their distinct effects. This allows avoiding the weaknesses of "umbrella constructs" and artificial dichotomies between family and non-family firms (e.g., Miller \& Le Breton-Miller, 2014). It also allows broadening the applicability of our theory to other classes of owners with different configurations of emotional attachment and power concentration. 


\section{MECHANISMS LINKING FAMILY OWNERSHIP TO AC}

Drawing on prior literature, we have distilled two dimensions, emotional attachment and power concentration, that qualify the type of family owner influence and position the different forms that it can take within a multi-faceted continuum in relation to shaping firm strategy and structure. We use these two dimensions to build a theory on the mechanisms linking family ownership to AC. There is currently no theory of the effects of family ownership on $\mathrm{AC}$, which constitutes a major knowledge gap. Based on corporate governance, cognitive psychology, and AC research, we elaborate on the model of family owner influence illustrated in the previous section to examine the specific mechanisms through which family ownership can influence knowledge acquisition and exploitation. This analysis allows considering the contingency factors that contribute to determining the ultimate effect of family ownership on AC.

Proposition 1 (P1): Family ownership influences the firm's AC through emotional attachment, such that the strength of family owner emotional attachment (a) decreases the level of potential AC and (b) increases the level of realized AC.

Proposition 2 (P2): Family ownership influences the firm's AC through power concentration, such that the extent of power concentration (a) increases the level of potential AC and $(b)$ decreases the level of realized $A C$.

\section{THE PARADOXICAL EFFECTS OF FAMILY OWNERSHIP ON AC}

Our analysis has identified two key mechanisms through which family ownership can facilitate and hamper AC. Specifically, we argue that family ownership hinders the development of potential AC but assists the development of realized AC as the family owners' emotional attachment to the firm strengthens. Conversely, family ownership has a positive effect on potential AC and a negative effect on realized AC as power is concentrated in family owners. As such, our analysis suggests that the influence exerted by family ownership on AC through emotional attachment and power concentration is misaligned and therefore has decisive implications on the ultimate effect of family ownership on the firm's ability to acquire and exploit new external knowledge.

\section{Motivation gap}

With respect to potential AC, power concentration endows family owners with greater discretion and latitude of action (Carney, 2005). Thus, power concentration increases the firm's ability to search broadly, without the need to observe bureaucratic or administrative constraints.

Nevertheless, the emotional attachment of family owners leads these decision-makers to undervalue external knowledge (König et al., 2013; Kotlar et al., 2013) and hence reduces the firm's willingness to acquire knowledge outside existing domains. In other words, the combination of the positive effects associated with power concentration and the negative effects associated with emotional attachment suggests that family ownership affects potential AC in both upward and downward directions, possibly resulting in extremely high and extremely low degrees of potential AC depending on the specific combination of emotional attachment and power concentration in the 
respective firm. We can thus reasonably expect to observe higher heterogeneity in potential AC across firms with higher degrees of family ownership. The dotted box in Figure 1 illustrates the possible effects of family ownership on potential $\mathrm{AC}$, where the upper and lower limits respectively represent a firm's willingness to acquire external knowledge and its ability to do so. The actual level of potential AC, illustrated by the gray area in Figure 1, will become higher (lower) as the motivation gap between willingness and ability becomes smaller (larger). The consequences of family ownership on potential AC are difficult to predict due to the inconsistency of the effect on the strategy and structure dimensions. The ultimate effect depends primarily on the motivation gap between the greater ability and lower willingness to acquire external knowledge, and thus on contingencies that strengthen or weaken family owner influence on firm strategy through emotional attachment.

\section{Implementation gap}

With respect to realized $\mathrm{AC}$, the reluctance towards external knowledge caused by family owner emotional attachment lessens and is replaced by incentives to exploit the acquired knowledge resources for commercial ends (Carney, 2005; Duran et al., 2015; Patel \& Chrisman, 2014). Thus, emotional attachment increases the firm's willingness to exploit external knowledge once acquired. Yet, power concentration in family owners isolates them from the rest of the organization (Ibarra, 1992), which reduces the incentive of lower-rank managers and employees to actually implement such new knowledge in existing processes and products (Lenox \& King, 2004; Patel \& Cooper, 2014). Thus, power concentration reduces the firm's ability to exploit newly acquired knowledge. For these reasons, as for potential AC, the simultaneous influence of emotional attachment and power concentration can reasonably increase the heterogeneity of realized AC among firms. The possible effects of family ownership on realized AC are illustrated in the dotted box in Figure 1. The actual level of realized AC (the gray area in the figure) will become higher (lower) as the implementation gap between ability and willingness to exploit external knowledge becomes smaller (larger). Therefore, our analysis suggests that the ultimate effect of family ownership on realized $\mathrm{AC}$ varies according to the size of the implementation gap between the family owner's higher willingness and lower ability to acquire external knowledge and thus depends on contingencies that increase or decrease the influence of family owners on firm structure through power concentration.

\section{CONTINGENCIES DETERMINING FAMILY OWNERSHIP EFFECTS ON AC}

Our analysis suggests that family ownership is an important internal driver of AC heterogeneity but such influence can be both positive and negative. By outlining the two key mechanisms through which family ownership influences potential and realized AC, namely, emotional attachment and power concentration, our theoretical approach helps identify and classify the contingency factors that, by operating on the specific mechanisms outlined above, can cause positive or negative family ownership effects to prevail.

Proposition 3 (P3): Ceteris paribus, the motivation gap becomes larger and the negative effect of family ownership on potential AC prevails when (a) family owners strongly identify with the firm or (b) family owners have strong family control intentions. 
Proposition 4 (P4): Ceteris paribus, the motivation gap becomes smaller and the positive effect of family ownership on potential AC prevails when (a) the firm faces negative performance feedbacks or (b) the firm faces control threats.

Proposition 5 (P5): Ceteris paribus, the implementation gap becomes larger and the negative effect of family ownership on realized AC prevails in the presence of (a) a family CEO or (b) family members involved in top management.

Proposition 6 (P6): Ceteris paribus, the implementation gap becomes smaller and the positive effect of family ownership on realized AC prevails in the presence of (a) high family ownership dispersion or (b) institutional investments.

\section{DISCUSSION AND CONCLUSION}

This article contributes insights that extend current understanding of $\mathrm{AC}$ by introducing firm ownership in the debate on its organizational antecedents. Focusing on the consequences of firm ownership in terms of how firms manage external knowledge acquisition and exploitation, our analysis extends the current $\mathrm{AC}$ discussion beyond purely rational considerations to explain how emotional concerns affect the cognitive mechanisms underlying AC.

Our analysis shows two key paradoxes, the motivation and implementation gaps, reflecting the tension between the firm's willingness to develop AC and its ability to do so. The notion that $\mathrm{AC}$ requires both ability and willingness is implicit in prior conceptualization of the construct (e.g., Cohen \& Levinthal, 1990; Lane et al., 2006). However, most research into the antecedents of AC is limited to an ability-based view that takes willingness for granted. The antecedents that influence a firm's willingness to acquire and exploit external knowledge are empirically less scrutinized than the firm's ability to do so (Lane et al., 2006; Todorova \& Durisin, 2007; Volberda et al., 2010), which constitutes a further research area.

By examining the influence of family owners on $\mathrm{AC}$, this article also addresses an important debate on innovation in family firms (De Massis et al., 2013). Our theoretical analysis goes beyond previous approaches by advancing a systematic reconceptualization of family owner influence and reconciles the divergent views by differentiating the effect of family ownership on external knowledge exploration and exploitation. Our focus on AC allows reconciling the divergent views by highlighting the contradictions between firm owner emotional attachment and power concentration in relation to external knowledge. In particular, we demonstrate that these contradictory dimensions produce motivation and implementation gaps that explain why family ownership can increase the heterogeneity and variability of AC.

This analysis not only sheds light on the mechanisms underlying AC in family owned firms, but leads to understanding the importance of contingency factors and temporal aspects to predict the consequences of family ownership on innovation.

\section{REFERENCES AVAILABLE FROM THE AUTHORS}

